\title{
Experimental and computational studies of wind loads on the airport complex
}

\author{
Pavel Churin ${ }^{1, a}$, Olga Poddaeva ${ }^{1}$ \\ ${ }^{1}$ Moscow State University of Civil Engineering (MGSU), Russian Federation, Moscow, 26 \\ Yaroslavskoe shosse \\ apashok_@inbox.ru
}

Keywords: Aerodynamics, unique buildings, wind loads, experimental research, wind tunnel, aerodynamic coefficients.

\begin{abstract}
The paper considers the questions of computational and experimental modelling of wind loads on unique buildings and structures by the example of the planned airport complex in the city Perm. The basic stages of research are prototyping, computational and experimental simulation of wind load. The results of investigations.
\end{abstract}

\section{Introduction}

Since the beginning of this decade in the territory of the Russian Federation, a development of unique buildings and constructions is actively conducted. These constructions primarily include large sports complexes, shopping malls and airport terminals. This is due first and foremost by a large number of international sporting events, the most significant of which are the Sochi Olympics, held in 2014, and the FIFA World Cup, which will be held in 2018 in several major cities of our country.

Designing these unique objects is an extremely difficult and responsible process. One of the most important stages of the design is keeping loads on the future construction. In this paper, we will discuss computational and experimental simulation of wind loads on a unique building by the example of the passenger terminal in the city Perm (Figure 1). Carrying out such a simulation is regulated by the SP 20.13330.2011 "Loads and effects."

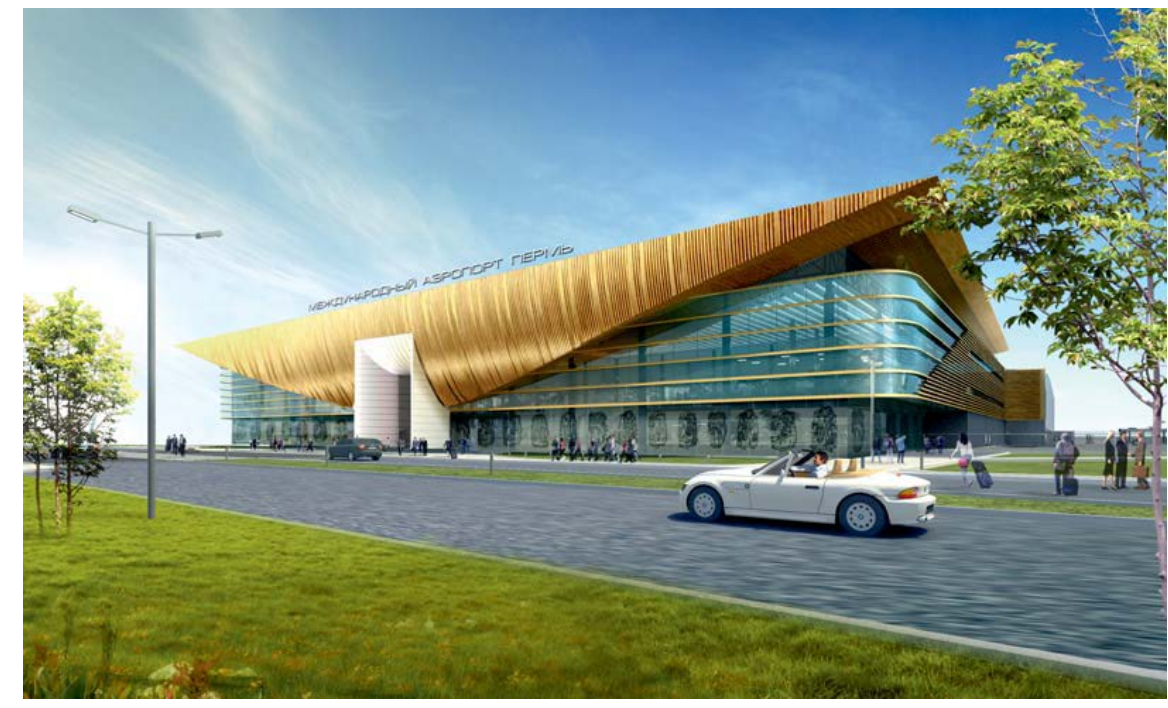

Fig. 1 Airport complex in Perm

According to SP 20.13330.2011 the characteristic value of wind load should be set in one of two ways. In the first case, the load is a set of normal pressure applied to the outer surface of a structure or element; friction forces directed tangentially to the outer surface and referred to the area of its horizontal or vertical projection; normal pressure applied to the inner surfaces of the structures with permeable barriers, open or permanently open apertures. Thereafter, in the simulation for estimating 
the wind load on the structure, we need to determine the distribution or aerodynamic pressure on the outer surface facilities coefficient or coefficients of aerodynamic resistance and torque.

Computational and experimental simulation described in the article is one of the most effective methods for the determination of wind loads, as it combines the main advantages of physical modelling in a special wind tunnel architectural and construction type and numerical simulation in certified software packages of gas-hydrodynamics [1, 2].

In the first stage of the research carried out manufacturing of the layout of the object for experimental studies and computer models for modelling in software package. Integral aerodynamics (drag coefficient and torque - Cx, Cy and Cmz) determined during the experimental studies, traditionally considered to be the most reliable. Full distribution of aerodynamic pressure coefficient on the surface of the object is determined in the process of numerical simulation. The authenticity numerical simulation results is confirmed by verification with the data of experimental studies conducted in several control points on the layout surface. Thus the customer receives the most complete and reliable results in a fairly short period of time.

The studies were conducted on the basis of educational, scientific and industrial laboratory for aerodynamic and aeroacoustic tests of building structures of the Moscow State University of Civil Engineering.

\section{Layout}

For experimental studies manufactured model of the passenger terminal of the airport complex was designed and considering the size of the working part of the wind tunnel (cross section 4x2,5 meters) and conditions of flow blockage the biggest scale of layout was chosen (1:250).

The main requirement to the model for aerodynamic testing, a strict observance of the geometric similarity of the object under study.

In view of definition the integral features aerodynamic characteristics in the course experiment, one of the most important elements of the layout is its foundation. It provides a rigid connection of the sensor used to determine the force-torque characteristics to eliminate the influence of external vibration on the readings of the measuring equipment.

Elements of the roof due to the complex spatial geometric forms were made on 3D Cube Pro printer. Fixing elements of the roof to the model suggests the possibility of dismantling, in order to accommodate high-pressure sensors in the roof space, and of the pneumatic route to the control points on the layout surface (Figure 2).

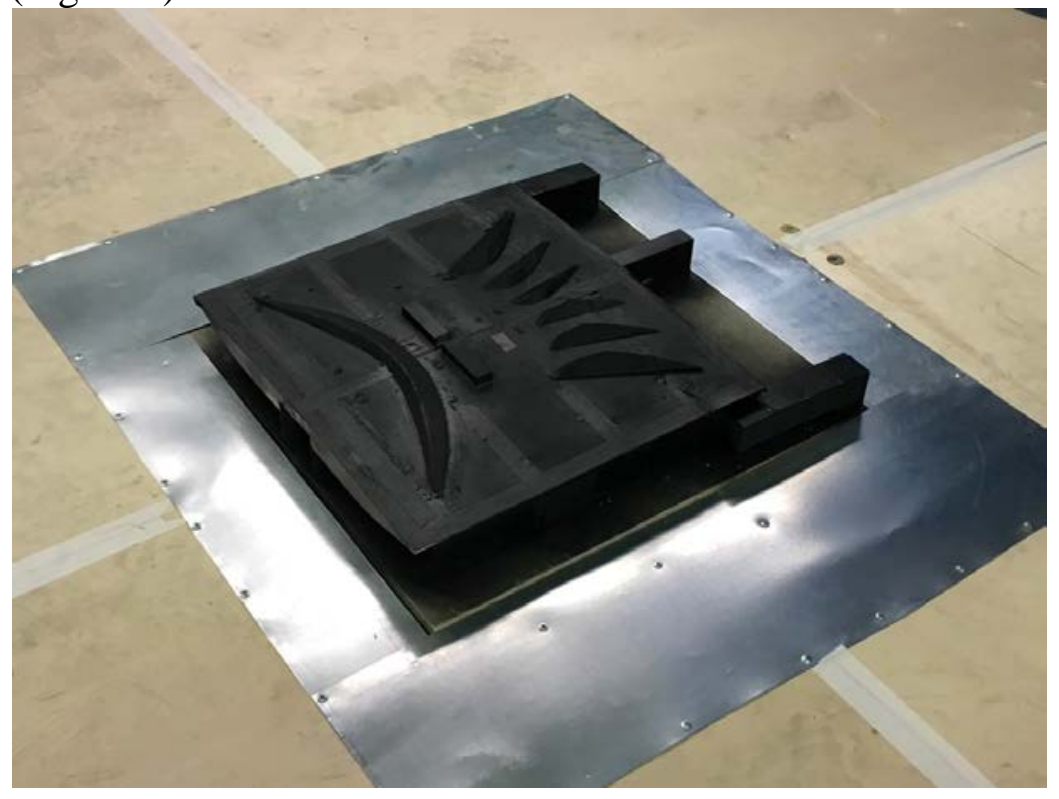

Fig. 2 Layout 


\section{Test set}

The wind tunnel of the Moscow State University of Civil Engineering (Figure 3) was used as a test bed for experimental studies. The wind tunnel has a closed circulation loop and modular fan unit of nine units, with a length of the working zone in the working area of 18.9 meters. The length of the working area allows you to edit the profile of epures the flow rate, simulating the surface layer of the atmosphere under various conditions. Range of speeds in the working zone: from 0 to $32 \mathrm{~m} / \mathrm{s}$.

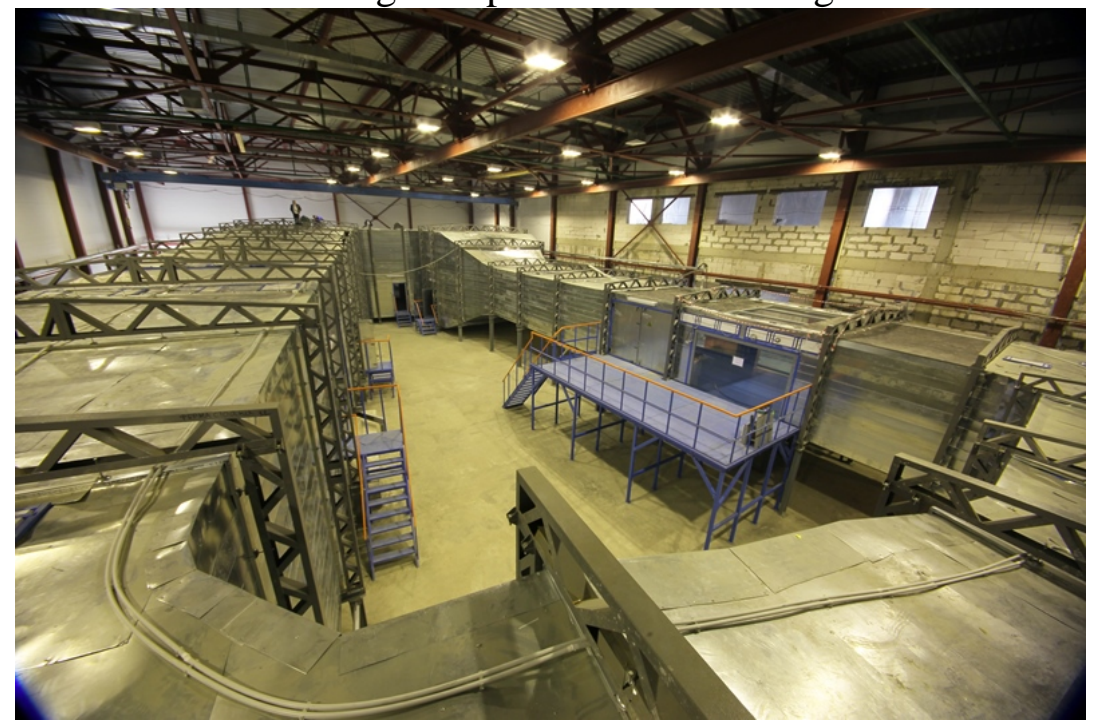

Fig. 3 Wind tunnel

\section{The study of wind load}

During the tests of large-scale model $(1: 250)$ in a wind tunnel a coincidence to the natural number of Reynolds is unattainable [1]. However, bodies of a similar class (badly streamline) are characterized by the existence of "self-similarity on Reynolds's number" meaning with the increasing Re dimensionless body flow characteristics are practically independent on this parameter [2]. The basic measurement cycle performed at a flow rate $\mathrm{v}_{\infty}=20 \mathrm{~m} / \mathrm{s}$, which corresponds to $\mathrm{Re}=0.38 * 106$.

Using six-component force-torque sensors and ATI DAQ F/T software the total force (tf) and torques along the axes $\mathrm{X}, \mathrm{Y}$ and the $\mathrm{Z}$, respectively (Fx, Fy, Fz, Mx, My and Mz) are being defined, and the total coefficient of aerodynamic resistance relative to the axes $\mathrm{X}, \mathrm{Y}$ and $\mathrm{Z}$, respectively $(\mathrm{Cx}$, $\mathrm{Cy}, \mathrm{Cz}, \mathrm{CMx}, \mathrm{CMy}$ and $\mathrm{CMz}$ ) are calculated.

Figure 4 shows a plot of aerodynamic coefficient from angle of attack.

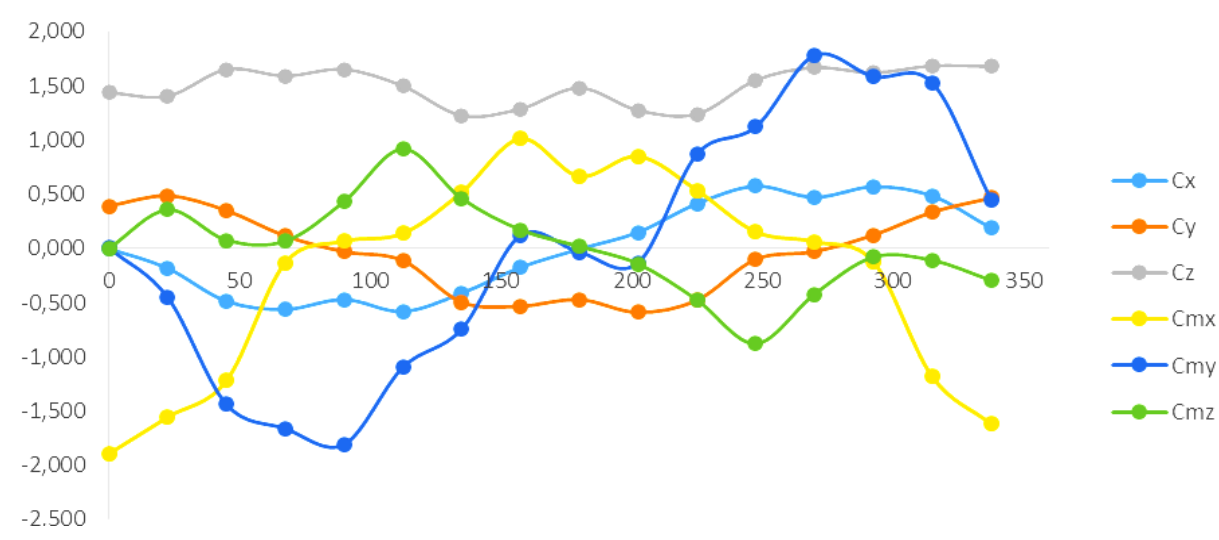

Fig. 4 The dependence of the coefficients values Cx , Cy, Cz, CMx, CMy and CMz from attack angle.

The values of the aerodynamic pressure coefficients are determined in two ways: 
- the complete picture of the aerodynamic pressure coefficient $\mathrm{Cp}$ distribution on the construction's facades and roof are determined by numerical simulation using the software package ANSYS [3, 4] (Figure 5);

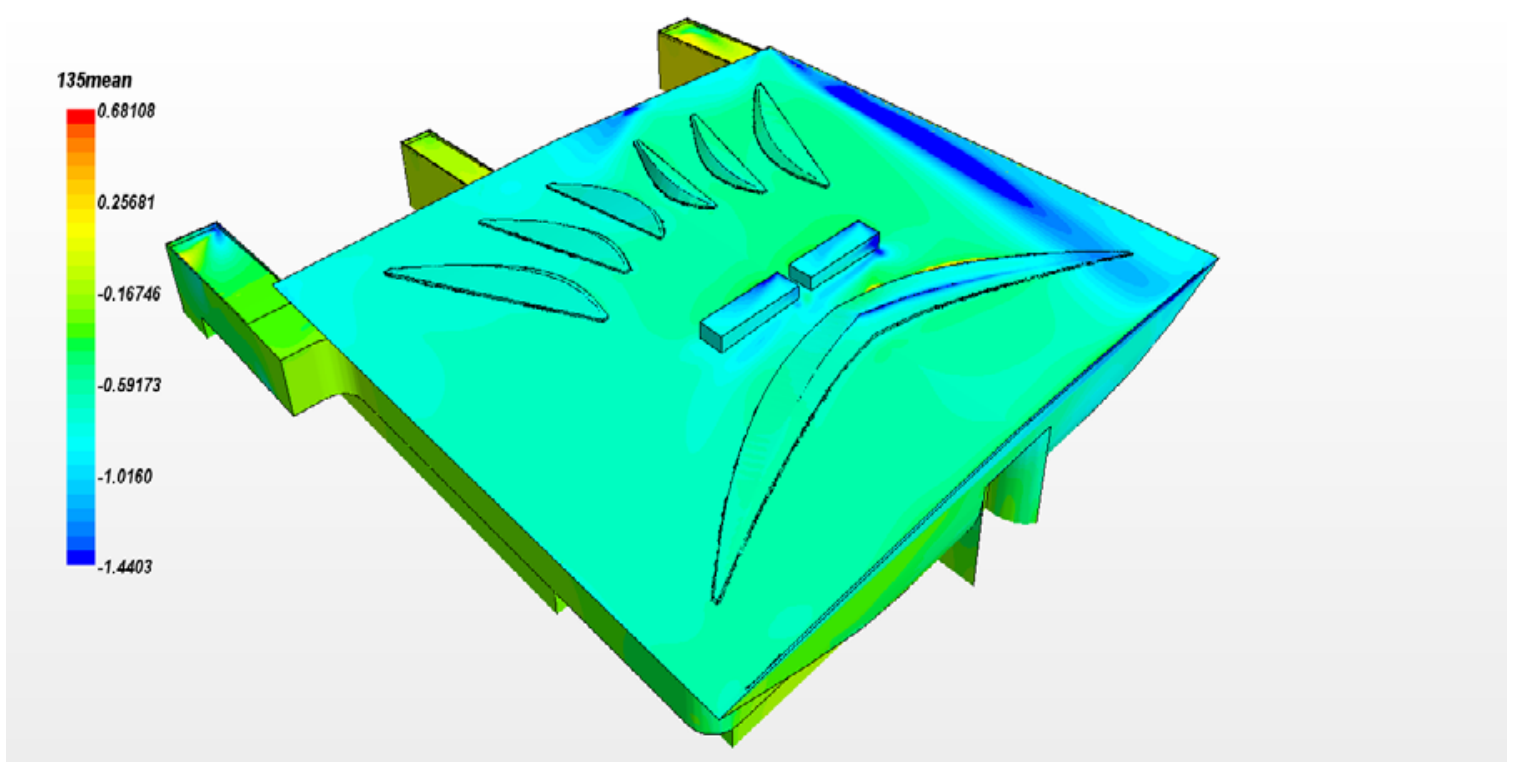

Fig. 5 The average coefficient of aerodynamic pressure distribution the on the facades of the airport complex terminal for wind direction $135^{\circ}$

- The value of the aerodynamic pressure coefficients at the control points on the layout surface is determined experimentally in a wind tunnel in order to verify the numerical simulation results $[5,6]$ (Figure 6).

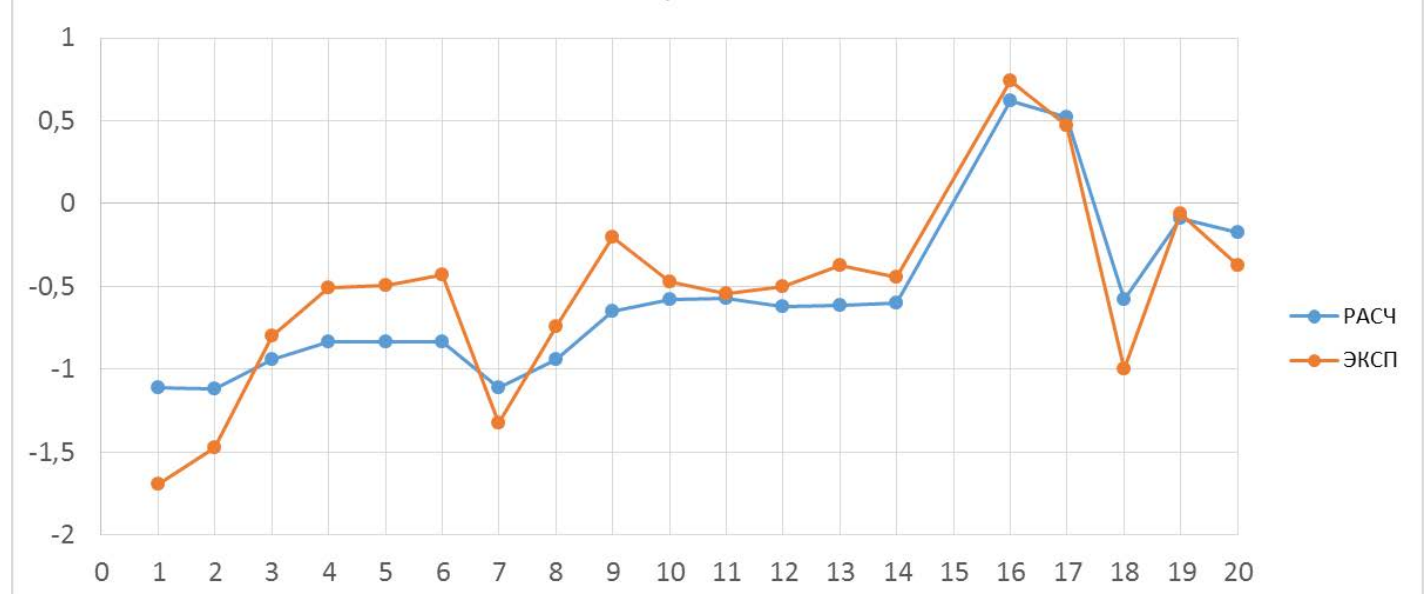

Fig. 6 Results verification

\section{Conclusion}

The complex configuration of the airport terminal complex leads to the formation of numerous vouchers and jet vortex zones, which interact with each other and a picture of the non-monotonic distribution of wind pressure on the airport complex terminal facades is formed.

The results received within carrying out settlement and experimental simulation are necessary for the designer for exact calculation of construction loads. Using the results of modelling could either reduce or increase the size of the load on the structure obtained in the pre-design stage with analytical calculations and related schemes of the joint venture.

In present time a carrying out the similar tests is obligatory for unique buildings and constructions and objects with the heightened responsibility degree. 


\section{Acknowledgement}

This work was financially supported by the Ministry of Education and Science as a part of the state task MGSU № 2014/107, the project "Fundamental studies of wind effects (including extreme) on the unique building and bridge structures"

\section{References}

[1] J.D.Holmes. Wind loading of structures. CRC Press (2015).

[2] O.I. Poddaeva, J.S. Buslaeva, D.S. Gribach. Physical model testing of wind effect on the high-rise, Advanced Materials Research, 1082. p. 246. (2015)

[3] T. van Hooff, B. Blocken, M. van Harten. 3D CFD simulations of wind flow and wind-driven rain shelter in sports stadia: influence of stadium geometry, Build Environ, 46 (2011), pp. 22-37

[4] O. O. Egorychev, S. I.Dubinsky, A. N. Fedosova, High-Rise Residential Complex Wind Aerodynamics Simulation. Applied Mechanics and Materials, Vol. 713, pp. 1729-1732, (2015)

[5] I.V. Dunichkin, D.A. Zhukov, A.A. Zolotarev. The effect of aerodynamic parameters of high-rise buildings on the microclimate and aeration urban environment, Promyshlennoe i grazhdanskoe stroitel'stvo, 9, pp. 39-41 (2013)

[6] M. Kanda, E. Maruta. Characteristics of fluctuating wind pressure on long low-rise buildings with gable roofs. J Wind Eng Ind Aerodyn, 50 (1993), pp. 173-182 